\title{
La medicina legal y forense y la dermatología
}

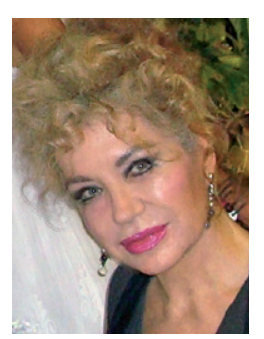

Aurora Guerra-Tapia

Profesora titular de Dermatología.

Departamento de Medicina.

Facultad de Medicina.

Universidad Complutense

de Madrid.

Exjefa de la Sección

de Dermatología.

Hospital Universitario

12 de Octubre. Madrid.

Directora del Máster

en Dermofarmacia

y Formulación Cosmética.

Universidad Internacional

de La Rioja (UNIR).

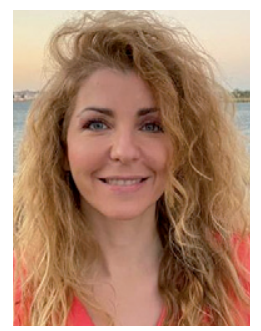

Elena González-Guerra

Profesora asociada

de Dermatología.

Facultad de Medicina.

Universidad Complutense

de Madrid.

Médico adjunto

del Servicio de Dermatología.

Hospital Clínico San Carlos.

Madrid.

Directora del Máster

en Dermofarmacia

y Formulación Cosmética.

Universidad Internacional

de La Rioja (UNIR).

\author{
«Considero que los crímenes pueden ser \\ diagnosticados igual que las enfermedades \\ si se utilizan las mismas técnicas». \\ (Sherlock Holmes: el comienzo) \\ Sir Arthur Conan Doyle (1859-1930)
}

La sección «El beso de la mariposa» de la revista Más Dermatología (www.masdermatologia.com; ISSN 20137338), a la que ya podemos considerar mayor de edad, pretende que el arte o la cultura en cualquiera de sus aspectos roce a la dermatología, aunque de manera leve tal como lo haría un aleteo de mariposa, que es como besan estos hermosos insectos según dicen los cuentos de hadas. De esta forma lo anhelaba yo al inicio de la sección ${ }^{1}$ : «Así desearía que fueran cada uno de los renglones escritos a continuación: un destello, una brisa fresca, una mirada aguda, un dibujo multicolor, un mosaico que, como un Proteo repetido en infinitas variaciones, encierre en cada azulejo la solución al jeroglífico de misterios inéditos, de hechos insospechados, de perfiles y rostros desconocidos... Y todos ellos en relación con la dermatología. La historia, la pintura, las curiosidades, las efemérides, el cine, las biografías, el periodismo, el humor, los mitos... Todas esas caricias rozando la piel».

Para cumplir nuestro objetivo, hemos hablado desde esta tribuna de novela, refranes, historia, comicidad, música, cine, magia, publicidad... siempre en relación con la dermatología.

Pero hoy, sin salirme del programa - excusatio non petita, accusatio manifesta - vengo a hablar de una especialidad médica que también es arte dermatológico: la medicina legal y forense.

Hace bastantes años - muchos o pocos, todo es relativo-, me interesó el mundo forense. Estudié, me presenté a la oposición y saqué el nada despreciable número 6 (fig. 1). El examen, oral y a bola —esto es, sacando de un bombo tres números que correspon- 


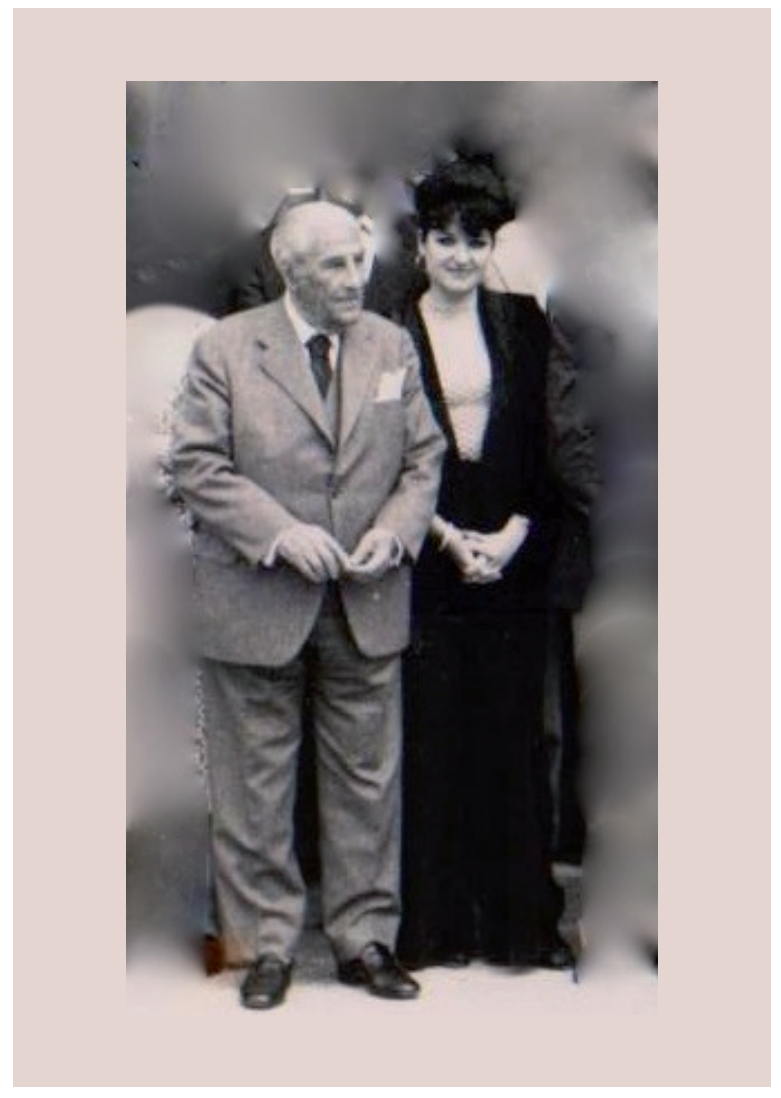

Figura 1. Aurora Guerra-Tapia al acabar las prácticas de medicina legal y forense, tras obtener el número 6 de la oposición, con el profesor Manuel Pérez de Petinto y Bertomeu.

dían respectivamente a las lecciones de medicina legal, psiquiatría y toxicología-, era duro. Recuerdo que tuve que hablar del infanticidio, la memoria y la clasificación de los psicofármacos, delante de un tribunal con toga y caras serias. Al fin y al cabo, estaban juzgando. Aprender esas materias enriquecía no solo en ciencia, sino también en cultura sin ninguna duda. A partir de ahí y durante algunos años, compaginé mis dos especialidades, encontrando que ambas tenían mucha más relación de lo que aparentemente podía parecer.

En las muertes súbitas o violentas había que determinar las causas, analizando la escena del óbito y los datos de la autopsia judicial. La apariencia externa del cuerpo permitía obtener información fidedigna para un dermatólogo, acostumbrado a distinguir la piel sana de la enferma o la agredida. El informe de autopsia era como una historia clínica post mortem. Anamnesis recogida de las circunstancias, la exploración externa de la piel y de los órganos, la recogida de muestras y los análisis toxicológicos...

Igual de útil era el conocimiento de la piel a la hora de valorar las lesiones de personas sobre las que determinar si habían sufrido una agresión o un accidente (quemaduras, heridas, contusiones...). A veces, los protagonistas se presentaban con intención de obtener algún beneficio, arguyendo enfermedades cutáneas como un liquen escleroso genital alegando una violación ilusoria, o con lesiones autoprovocadas para acusar falsamente a un agresor inocente o conseguir una indemnización que no merecían. Del mismo modo, era y es fundamental el conocimiento de la piel para discriminar el maltrato infantil o del anciano frágil, tanto por acción como por omisión ${ }^{2}$, o la urticaria autoprovocada, por ejemplo, ingiriendo aquello que ya saben que la produce en su caso, para librarse de una función social como el servicio militar o el ser vocal de una mesa de votación ${ }^{3}$.

En el campo de los tóxicos, es indudable que una gran parte de ellos manifiestan su efecto en la piel, tanto ingeridos como inhalados o por penetración cutánea, de forma crónica o aguda. Así, se puede distinguir entre una enfermedad profesional, una intoxicación accidental o con intención criminal $^{4}$. O incluso, aunque menos frecuente, un síndrome de Münchhausen en el que se desea la apariencia de una enfermedad determinada en uno mismo o en otro cercano.

Así ocurre con las intoxicaciones por arsénico (uñas de Mees -leuconiquia transversal-y cáncer de piel), por dioxinas (erupción acneiforme), por setas shiitake (pigmentación flagelada), por mercurio (síndrome del babuino, dermatitis de contacto sistémica en nalgas y flexuras), por talio (alopecia por efluvio anágeno), por plomo (tatuajes mucosos, ribete de Burton), por plata (pigmentación grisácea-argiria), y tantos otros casos (fig. 2). 

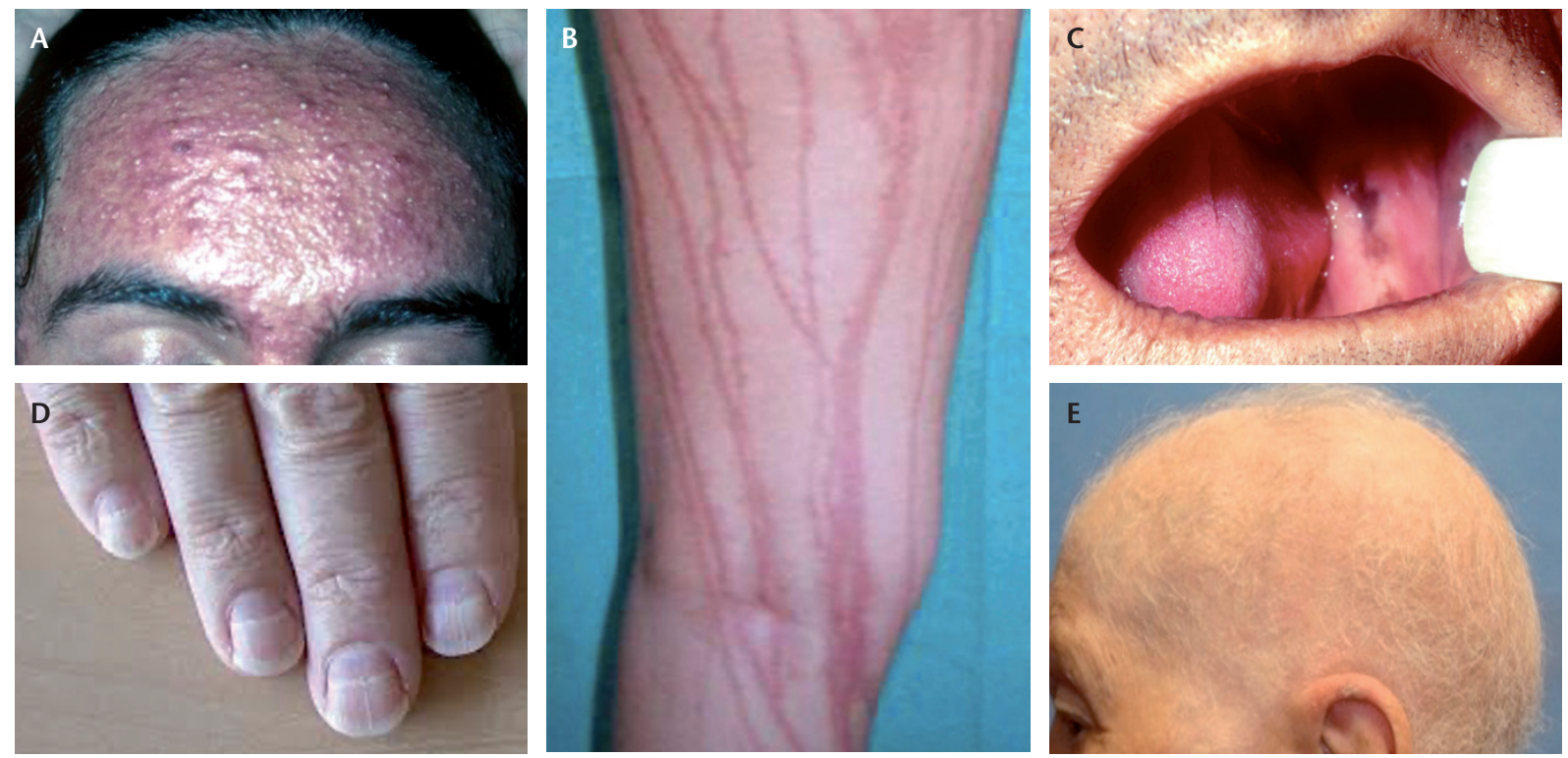

Figura 2. Imágenes clínicas de las manifestaciones cutáneas de diversas intoxicaciones. El diagnóstico dermatológico puede ser de gran ayuda en el diagnóstico forense. A) erupción acneiforme por dioxinas, B) pigmentación flagelada por setas shiitake, C) tatuaje mucoso por plomo, D) uñas de Beau por intoxicación sistémica y E) alopecia por talio.

En el mundo de la justicia, la relación del médico forense con otras especialidades es fundamental: bioquímicos, genetistas, traumatólogos, neurólogos, informáticos, anatomopatólogos... Uno de los especialistas más requeridos como consultor o perito es el dermatólogo.

La dermatología y la medicina forense tienen mucho más en común de lo que podría parecer, a tenor de los ejemplos referidos.

¿Y el arte? Además del arte individual con el que se nutre el ejercicio de esta interesante especialidad, en el mundo de la literatura y el cine, existen multitud de ejemplos de médicos forenses: eruditos, tenaces, metódicos, observadores, ecuánimes, éticos, con capacidad de comunicación, con habilidad para trabajar en equipo... como Hércules Poirot de Agatha Christie, Sherlock Holmes de Sir Arthur Conan Doyle, el teniente Colombo de William Link y Richard Levinson, la señora Fletcher de Jessi Klein, el inspector Tom Barnaby de Caroline Graham, la comandante Candice Renoir de Solen Roy-Pagenault...

¡Y me acabo de dar cuenta de que ninguno de ellos es médico forense! Y tampoco dermatólogo.

Pero... ¿a que lo parecen?

\section{BIBLIOGRAFÍA}

1. Guerra-Tapia A. Don Quijote de la Mancha. Más Dermatol. 2010; 10:28-9. Disponible en: https://masdermatologia.com/ PDF/0061.pdf

2. Moreno A, Hor A, Valencia V, lacopino V. Attitudes and experiences of health professionals towards clinical evaluations of torture and ill-treatment. J Forensic Leg Med. 2020;78:102107.

3. Baruffi FY, Venkatesh KP, Nelson KN, Powell A, Santos DM, Ehrlich A. Systemic contact dermatitis: a review. Dermatol Clin. 2020;38(3):379-88.

4. Luordo D, Forrester Zapata D, Lorenzo Mouronte S, Encabo Fernández F, Guerra-Tapia A. Manifestaciones cutáneas de las intoxicaciones por arsénico, plomo, mercurio y plata. Más Dermatol. 2014;23:4-11. Disponible en: https://masdermatologia.com/PDF/0147.pdf 